Original article

\title{
"Factors influencing the outcome of COVID-19 patients admitted in a tertiary care hospital, Madurai.- a cross-sectional study"
}

\author{
S. Priya, M.D. (Community Medicine), D.G.O ${ }^{\text {a }}$, M. Selva Meena, M.D. (Community Medicine) ${ }^{\text {a, * }}$, \\ J. Sangumani, M.D. (General Medicine) D. Diab ${ }^{\mathrm{b}}$, Prabhakaran Rathinam, M.D. Respiratory \\ Medicine $^{\mathrm{c}}$, C. Brinda Priyadharshini, Postgraduate in Community Medicine ${ }^{\mathrm{a}}$, V. Vijay Anand, \\ Postgraduate in Community Medicine ${ }^{a}$
}

${ }^{a}$ Institute of Community Medicine, Madurai Medical College, India

${ }^{\mathrm{b}}$ Government RajajiHospital(GRH) and Madurai Medical College, India

${ }^{\mathrm{c}}$ COVID19 \& HOD of the Department of Respiratory Medicine, Madurai Medical College, Madurai, India

\section{A R T I C L E I N F O}

\section{Keywords:}

COVID19

Case investigation forms

Multivariate logistic regression

Survival probability

Global health emergency

\begin{abstract}
A B S T R A C T
Introduction: COVID19* is a new disease with significant mortality risk. Because of the scarcity of the study on factors associated with the mortality in Tamil Nadu present study was done to determine the factors associated with the outcome of the COVID19 patients admitted in a tertiary care hospital, Madurai.

Methodology: 4530 lab confirmed COVID19 patients admitted from March to August 31st' 2020; excluding the non-responders or who gave incomplete information were included in the study. Data retrieved from Case Investigation Forms *filled through telephonic interview. Chi -square test, Univariate and multivariate logistic regression were used to find out the association between the factors and risk of death(outcome).

Results: Out of 4530 COVID19 positive patients 381(8.4\%) died and 4149(91.6\%) were discharged. Using multivariate logistic regression* following were the factors predicted to be associated with mortality:Age group $<17 \mathrm{yrs}(\mathrm{PR}=4.12), 30-44 \mathrm{yrs}(\mathrm{PR}=2.28), 45-59(\mathrm{PR}=3.12), 60-69(\mathrm{PR}=4.26)$ and $\geq 70(\mathrm{PR}=7.05)$; male gender( $\mathrm{PR}=1.26)$; breathlessness at the time of admission( $\mathrm{PR}=7.05)$; with 1 symptom ( $\mathrm{PR}=2.58)$, 2symptoms $(\mathrm{PR}=3.16)$ and $\geq 3$ symptoms $(\mathrm{PR}=2.45)$; chronic kidney disease $(\mathrm{PR}=3.07)$, malignancy $(\mathrm{PR}=2.39)$; other chronic diseases $(\mathrm{PR}=1.89)$; having only diabetes $(\mathrm{PR}=1.58)$; diabetes with hypertension $(\mathrm{PR}=1.70)$; diabetes with heart disease $(P R=1.94)$; Hypertension with heart disease $(P R=2.30)$; diabetes with hypertension and heart disease $(P R=1.58)$. Survival probability* was more than $90 \%$ when patient gets admitted within a week after symptom onset, $<80 \%$ for between 7 and 10 days and declines thereafter.

Conclusion: Early insights into factors associated with COVID-19 deaths have been generated in the context of a global health emergency *which may help the treating physician.
\end{abstract}

\section{Introduction}

In Wuhan city of China,27 cases of pneumonia of unknown cause emerged on December 2020. ${ }^{1}$ On January 30, 2020 novel CORONA virus was declared as public health emergency of international concern by WHO. ${ }^{2}$ WHO officially named it as COVID -19 on February 11, 2020. COVID virus is a RNA Virus and it spreads from person to person through droplets let out from the infected persons while coughing, sneezing, and talking. As of 14-10-2020, globally 10,74,817 deaths had occurred out of $3,74,23,660$ crore people affected by the disease. ${ }^{3}$ In India, 1,09,856
(1.53\%) deaths had occurred out of 71,75,880 affected individual. ${ }^{3}$

In Tamil Nadu, out of 6,61,264 people affected,10,314 had died due to COVID. ${ }^{4}$ In Madurai, 17,574 were affected and 398 had died due to COVID $-19{ }^{4}$. First death in India was in Karnataka on March 10, 2020. A 76-year-old man from Karnataka's Kalaburgi who passed away as a COVID suspect was later tested positive for COVID-19. ${ }^{5}$ The first death in Tamil Nadu was on $25{ }^{\text {th }}$ March 2020 . He was a 54-year-old building contractor and he belonged to the Madurai district. He was also the first case reported in our institution, admitted on March 22, 2020 and died on March 25, 2020. ${ }^{6}$

\footnotetext{
* Corresponding author. 53, ChairmanShanmugamroad, Sivakasi, Virudhunagar district, TamilNadu, India.

E-mail addresses: drpriyagsh@gmail.com (S. Priya),drselvameena2@gmail.com (M. Selva Meena), sangudr@yahoo.co.in (J. Sangumani), thelungcentre@gmail. com (P. Rathinam), cspriya13@gmail.com (C. Brinda Priyadharshini), drvijay1871993@gmail.com (V. Vijay Anand).
} 
COVID -19 is a new disease, which has emerged as a pandemic. A study done by Xiochen Le et al. found out that older age, underlying hypertension, had a highly significant association with the severity of COVID-19 on admission. The mortality was $1.1 \%$ in non-severe patients and $32.5 \%$ in severe patients. ${ }^{7}$ In another study done by "the OPEN safely collaborative", death was associated with older age,male gender, uncontrolled diabetes, severe asthma, and various other prior medical conditions. $^{8}$ M.Z. Islam et al. in their study found out that mortality risk was higher for patients with COPD,CKD,CAD, diabetes, hypertension, chronic liver disease, and malignancy. ${ }^{9}$

Studies on COVID 19 outcome are scarce in Tamil Nadu. Hence the need for the present study to help in understanding the factors associated with the outcome which will enable the treating physicians to provide treatment accordingly.

\section{Objective}

To determine the factors associated with the outcome of COVID-19 patients admitted in a tertiary care Hospital, Madurai, 2020.

\section{Methodology}

This analytical cross-sectional study was done in a tertiary care hospital, which has a dedicated COVID wing and a COVID Health Centre attached to it. Its catchment area extends to the nearby villages and districts surrounding it. Our hospital is a government run hospital providing care to more than 31.6lakh (2011 census) people in Madurai and neighbouring districts. As on august 31,2020, our district had 5 COVID19 Hospitals, 25 COVID19 Health Centres,10 COVID19 Care Centres and the testing rate was $8.12 \%$. The positivity rate at our hospital during the same period was $3.88 \%$, mortality rate was $8.41 \%$, and recovery rate was $91.6 \%$, symptomatic proportion was $43.8 \%$.

The study period was two months from September to October 2020. All COVID -19 patients admitted in tertiary care hospital from March 2020 to August 2020(our reference period) were included in our study. 5204 lab-confirmed COVID positive cases were admitted in our institution including a COVID health centre attached to our institution from March $22{ }^{\text {nd }}$ to August 31st, 2020. Data regarding all those COVID patients were extracted from the Case Investigation Form(CIF) designed by NCDC. ${ }^{10}$ It had questions to collect data on a)socio-demographic factors like age,gender, occupation; b)symptoms, initial symptom, date of onset of symptoms, date of admission in our hospital, name and date of all the health care facilities visited before the admission in our hospital and reason for referral; c) known co-morbidity; d) contact history; e) travel history and f)swab details. The data on co-morbidity was cross verified with the lab reports and scanned case sheets regularly sent from the COVID ward to our team. If the data were unavailable, patients self reported information was relied upon.If the patient was sick, the primary care giver was interviewed.

CIF was filled on daily basis for all COVID positive patients based on the positive line list obtained from the COVID control room. This is an ongoing activity and is being done by our department. A trained team of our faculties, Postgraduates, and CRRIs collected data through telephonic interviews. For those who did not attend the call or number not reachable or under switched off,three attempts were made at an interval of three days.

Two researchers independently reviewed the data collection forms to double-check the collected data. This was done to improve the quality of data collected.

Patients who did not attend the phone call or whose numbers were not reachable or under switched off even after three attempts; those who did not give complete information; Patients who absconded or went against medical advice were excluded from our study. We got a final sample size of 4530 after applying the exclusion criteria. For the defined reference period of our study,we have included all the patients who got admitted in our tertiary care hospital(including COVID health centre attached to it).We calculated the power of our study to check the adequacy of our sample size using open epi software; risk factor with lowest prevalence in our study.i.e Malignancy(0.7\%) was taken for power calculation. The other parameters are:

Number of exposed persons $=30$.

Death among exposed $=50 \%$,

Number of non -exposed $=4500$.

Death among non-exposed $=8.13 \%$

Power of our study calculated was $100 \%$

Data collected in CIF were entered in the Google spreadsheet and the computerized data were maintained. Those data were extracted for analysis in this study. Age, gender, symptoms, and co-morbidities were independent variables, and Outcome (either discharge or death) was the dependant variable in our study. However, death was considered as the main outcome variable to analyze its association with the above-said factors.

The operational definition for COVID deaths -Death of laboratoryconfirmed COVID -19 patients that occurred in our institution with COVID as a primary and immediate cause of death. COVID19standard Treatment guidelines was followed in our hospital as per Clinical management protocol: COVID19 by MOHFW, Government of India [(version 1 (March 17, 2020), version 2 (March 31, 2020), version3 (June 13, 2020), version 4 (June 27, 2020), version 5 (July 03, 2020)].

Increase of target Spo2, inclusion of intravenous steroids and anticoagulants were the minor changes made in later versions ${ }^{11,12,13,14,} \cdot{ }^{15}$

Discharge policies as on March 17, 2020 was to discharge after 2 consecutive Rt-PCR negative reports within $24 \mathrm{~h},{ }^{16}$ and the policy was revised once on May 08, 2020 (discharge criteria was based on 1 Rt-PCR negative report for severe cases; clinical improvement and oxygen saturation maintenance at room air for moderate cases ${ }^{17}$ ). As per both the policies, only stable and recovered patients were discharged, so change in treatment and discharge policies would not have influenced our data. Home isolation criteria did not affect our study since only asymptomatics and patients without co-morbidity were given home isolation during our defined reference period.

The study protocol got approval from the Institutional Ethics Committee. Confidentiality of the patients was maintained throughout the study.

Data analysis was done in SPSS software version 21. Frequency and percentage for categorical variables; mean,standard deviation and range for continuous variables were found out using descriptive statistics. Comparison between categorical variables was done using Chi-square test or Fisher exact test. Univariate and multivariable logistic regression was done using generalized linear model-poisson loglinear to find out the association between the factors and risk of death (outcome) by estimating the unadjusted and adjusted prevalence ratio. P-value $<0.05$ was taken as a statistically significant value. Kaplan Meier survival analysis was done to find out the probability of survival of COVID patients.

\section{Results}

This report describes the factors associated with the outcome (death). Out of 4530 COVID positive patients included in our study, 381 (8.4\%) died and 4149 (91.6\%) were discharged. Since we have excluded the non responders and the responders who gave incomplete information, there was no missing data in our study.

Table 1 shows the age, gender, and outcome distribution of our study population. "Age" Variable was classified based on WHO steps classification for NCD because non-communicable diseases may increase the mortality risk among COVID patients. The majority of the respondents were males (60\%) and most of them were between the age group 45-59 years (30.4\%).Mean age was 46.59 and median was 48 , minimum age affected was two days and maximum was 92 years.

Table 2 depicts the socio-demographic factors and symptoms associated with the death using univariate analysis and Chi-square test. The 
Table 1

Distribution of age, gender and outcome of our study population $(\mathrm{N}=4530)$.

\begin{tabular}{llll}
\hline Age & Death & Discharge & Total \\
\hline$<17$ YRS & 7 & 186 & $193(4.3 \%)$ \\
$18-29$ YRS & 7 & 726 & $733(16.2 \%)$ \\
$30-44$ YRS & 37 & 983 & $1020(22.5 \%)$ \\
$45-59$ YRS & 104 & 1273 & $1377(30.4 \%)$ \\
$60-69$ YRS & 104 & 674 & $778(17.2 \%)$ \\
$>70$ YRS & 122 & 307 & $429(9.5 \%)$ \\
Total & $\mathbf{3 8 1 ( 8 . 4 \% )}$ & $\mathbf{4 1 4 9 ( 9 1 . 6 \% )}$ & $\mathbf{4 5 3 0 ( 1 0 0 \% )}$ \\
SEX & DEATH & DISCHARGE & TOTAL \\
Male & 287 & 2433 & $2720(60 \%)$ \\
Female & 94 & 1716 & $1810(40 \%)$ \\
Total & $\mathbf{3 8 1 ( 8 . 4 \% )}$ & $\mathbf{4 1 4 9 ( 9 1 . 6 \% )}$ & $\mathbf{4 5 3 0 ( 1 0 0 \% )}$ \\
\hline
\end{tabular}

proportion of death is lowest among the age group 18-29 years so that category was taken as the reference. Patients $\leq 17$ years were at 3.79 times higher mortality risk than 18-29 years. Among other age groups, the proportion of deaths and also the risk of death increased as age increased. The highest risk of death was observed among the age group $\geq 70$ years (28.4\%, PR -29.77).

When compared to females, males had a 2.03 times higher risk of dying $(10.6 \%, P R=2.03)$ which was statistically significant (p-value 0.000). Concerning symptoms, the association of breathlessness with death was analyzed separately as it could be considered as a proxy for
SPO2. It was inferred that patients who had breathlessness at the time of admission had a 14.98 times higher risk of death(41.5\%, PR - 14.98, pvalue 0.000 ) than those who got admitted without breathlessness.

With respect to symptoms other than breathlessness, the association between the number of symptoms and death was found out. It was evident from Table 2 that as the number of symptoms increased, the risk of death also increased with a PR of 4.68 for 1 symptom and 6.07 for 2 symptoms, 4.38 for 3 symptoms. All these differences were statistically significant.

Table 3 shows the association of co-morbidities with death. Mortality risk was more among those with Chronic Kidney Disease (CKD) (61.5\%, $\mathrm{PR}=8.59)$, malignancy $(50 \%, \mathrm{PR}=6.14)$, any pre-existing lung disease $(18.6 \%, P R=2.29)$, and patient with other chronic diseases like HIV, liver disease, neurological disorders, etc $(27.4 \% \mathrm{PR}=3.68)$ when compared with their counterpart (those who did not have that corresponding co-morbidity). 3 main co-morbidities namely Diabetes(DM), hypertension(HT), heart disease were analyzed separately and in multiple combinations to find their association with death.

Those who didn't have these 3 co-morbidities were taken as the reference category. It was inferred that on an average, COVID patients had at-least 3 times greater risk of mortality when they had at-least any one co-morbidity (PR was 3.48 for DM and 2.86 for HT and 2.92 for heart disease). The risk of death further increased when these comorbidities were present in combinations like DM with HT (proportion of deaths $=25.1 \%, P R=6.49)$, diabetes with heart disease $(28.6 \%$,

Table 2

Comparison and univariate analysis OF SOCIO-DEMOGRAPHIC factors and symptoms with death among COVID 19 PATIENTS(N = 4530).

\begin{tabular}{|c|c|c|c|c|c|c|}
\hline FACTORS & DEATH $(\mathrm{N}=381)$ & SURVIVORS $(\mathrm{N}=4149)$ & TOTAL & P VALUE BY CHI - SQUARE TEST & PREVALENCE RATIO (95\% CI) & P VALUE \\
\hline \multicolumn{7}{|l|}{ AGE IN YEARS } \\
\hline$\leq 17$ & $7(3.6 \%)$ & 186 & 193 & $<0.001^{\mathrm{b}}$ & $3.798(1.332-10.820)$ & $0.013^{\mathrm{b}}$ \\
\hline $18-29^{\mathrm{a}}$ & $7(1 \%)$ & 726 & 733 & & & \\
\hline $30-44$ & $37(3.6 \%)$ & 983 & 1020 & & $3.798(1.693-8.520)$ & $<0.001^{\mathrm{b}}$ \\
\hline $45-59$ & $104(7.6 \%)$ & 1273 & 1377 & & 7.909 (3.679-17.001) & $<0.001^{\mathrm{b}}$ \\
\hline $60-69$ & $104(13.4 \%)$ & 674 & 778 & & $13.998(6.512-30.091)$ & $<0.001^{\mathrm{b}}$ \\
\hline$\geq 70$ & $122(28.4 \%)$ & 307 & 429 & & $29.779(13.902-63.787)$ & $<0.001^{\mathrm{b}}$ \\
\hline \multicolumn{7}{|c|}{ 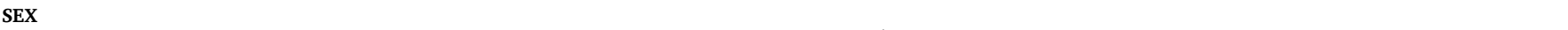 } \\
\hline Female $^{\mathrm{a}}$ & $94(5.2 \%)$ & 1716 & 1810 & $<0.001^{\mathrm{b}}$ & & \\
\hline Male & $287(10.6 \%)$ & 2433 & 2720 & & $2.032(1.610-2.565)$ & $<0.001^{\mathrm{b}}$ \\
\hline \multicolumn{7}{|l|}{ SYMPTOMS } \\
\hline Breathlessness & $274(41.5 \%)$ & 387 & 661 & $<0.001^{\mathrm{b}}$ & 14.989 (11.988-18.741) & $<0.001^{\mathrm{b}}$ \\
\hline \multicolumn{7}{|c|}{ NO OF SYMPTOMS } \\
\hline None $^{a}$ & $58(2.7 \%)$ & 2099 & 2157 & $<0.001^{\mathrm{b}}$ & & \\
\hline 1 & $154(12.6 \%)$ & 1068 & 1222 & & 4.687 (3.465-6.339) & $<0.001^{\mathrm{b}}$ \\
\hline 2 & $120(16.3 \%)$ & 615 & 735 & & $6.072(4.438-8.307)$ & $<0.001^{\mathrm{b}}$ \\
\hline$\geq 3$ & $49(11.8 \%)$ & 367 & 416 & & 4.381 (2.995-6.407) & $<0.001^{\mathrm{b}}$ \\
\hline
\end{tabular}

a - reference in binary logistic regression to find out univariate unadjusted prevalence ratio.

b P-value $<0.05$,statistically significant.

Table 3

Comparison and univariate analysis of comorbidities with death among COVID19 patients $(\mathrm{N}=4530)$.

\begin{tabular}{|c|c|c|c|c|c|c|}
\hline CO MORBIDITIES & DEATH $(\mathrm{N}=381)$ & SURVIVORS $(\mathrm{N}=4149)$ & $\begin{array}{l}\text { TOTAL } \\
\text { N (\%) }\end{array}$ & P VALUE BY CHI - SQUARE TEST & PREVALENCE RATIO (95\% CI) & P VALUE \\
\hline CKD & $64(61.5 \%)$ & 40 & 104 & $<0.001^{\mathrm{b}}$ & $8.592(6.568-11.239)$ & $<0.001^{\mathrm{b}}$ \\
\hline Malignancy & $15(50 \%)$ & 15 & 30 & $<0.001^{\mathrm{b}}$ & $6.148(3.668-10.302)$ & $<0.001^{\mathrm{b}}$ \\
\hline No DM/HT/CHD ${ }^{\mathrm{a}}$ & $117(3.9 \%)$ & 2907 & 3024 & $<0.001^{\mathrm{b}}$ & & \\
\hline Only DM & $86(13.5 \%)$ & 552 & 638 & & $3.484(2.637-4.602)$ & $<0.001^{\mathrm{b}}$ \\
\hline Only HT & $32(11.1 \%)$ & 257 & 289 & & $2.862(1.936-4.231)$ & $<0.001^{\mathrm{b}}$ \\
\hline only CHD & $6(11.3 \%)$ & 47 & 53 & & $2.926(1.288-6.646)$ & $0.010^{\mathrm{b}}$ \\
\hline DMwithHT & $99(25.1 \%)$ & 295 & 394 & & $6.494(4.969-8.487)$ & $<0.001^{\mathrm{b}}$ \\
\hline DMwith CHD & $14(28.6 \%)$ & 35 & 49 & & $7.385(4.242-12.854)$ & $<0.001^{\mathrm{b}}$ \\
\hline HTwith CHD & $7(25.9 \%)$ & 20 & 27 & & $6.701(3.126-14.366)$ & $<0.001^{\mathrm{b}}$ \\
\hline DM, HTand CHD & $20(35.7 \%)$ & 36 & 56 & & $9.231(5.745-14.832)$ & $<0.001^{\mathrm{b}}$ \\
\hline Lung disease & $22(18.6 \%)$ & 96 & 118 & $<0.001^{\mathrm{b}}$ & $2.291(1.490-3.524)$ & $<0.001^{\mathrm{b}}$ \\
\hline Other chronic disease & $61(27.4 \%)$ & 162 & 223 & $<0.001^{\mathrm{b}}$ & $3.682(2.800-4.841)$ & $<0.001^{\mathrm{b}}$ \\
\hline
\end{tabular}

CKD-Chronic renal disease, DM-Diabetesmellitus, HT-Hypertension, CHD -Heart disease.

a - reference in binary logistic regression to find out univariate unadjusted prevalence ratio.

b P-value $<0.05$,statistically significant. 
$\mathrm{PR}=7.38)$, hypertension with heart disease $(25.9 \%, \mathrm{PR}=6.70)$. Finally, the mortality risk was highest among those patients who had all three co-morbidities $(35.7 \% \mathrm{PR}=9.23)$. All these differences were statistically significant.

Table 4 shows the results of multivariate analysis with adjusted prevalence ratio for the factors associated with death. (i.e.prevalence ratio adjusted for all other factors listed). We identified risk factors like age $<17$ yrs,increasing age starting form $30 y r s$, male gender, having breathlessness alone or other multiple symptoms excluding breathlessness at the time of admission, pre-existing CKD,malignancy, hypertension with heart disease, DM as single co-morbidity or in multiple combinations(with hypertension or heart disease or both) were predicted to significantly increase the risk of mortality among COVID-19 patients. Prevalence ratio of individual factors were as follows. Age group $<17 \mathrm{yrs}(\mathrm{PR}=4.12), 30-44(\mathrm{PR}=2.28), 45-59(\mathrm{PR}=3.12), 60-69$ $(\mathrm{PR}=4.26)$ and $\geq 70$ ( $\mathrm{PR}=7.05)$; male gender ( $\mathrm{PR}=1.26)$; breathlessness at the time of admission( $\mathrm{PR}=7.05)$; with 1 symptom( $\mathrm{PR}=$ $2.58)$, 2 symptoms $(P R=3.16)$ and $\geq 3$ symptoms $(P R=2.45)$; preexisting chronic renal disease ( $\mathrm{PR}=3.07$ ), pre-existing malignancy ( $\mathrm{PR}=2.39)$; pre-existing other chronic diseases( $\mathrm{PR}=1.89)$; having only diabetes( $\mathrm{PR}=1.58)$; diabetes with hypertension ( $\mathrm{PR}=1.70)$; diabetes with heart disease $(P R=1.94)$ and hypertension with heart disease (PR $=2.30)$; diabetes with hypertension and heart disease $(\mathrm{PR}=1.58)$. Highest risk of mortality was predicted for those $\geq 70 \mathrm{yrs}(\mathrm{PR}=7.05)$, breathless at the time of admission ( $\mathrm{PR}=7.05$ ), presenting with preexisting $\mathrm{CKD}(\mathrm{PR}=3.07)$ or malignancy $(\mathrm{PR}=2.39)$.

Figs. 1 and 2 shows the survival curve of COVID patients admitted at different time intervals from the onset of symptoms and admission in

Table 4

Multivariate analysis of risk factors associated with death among COVID19 patients $(\mathrm{N}=4530)$.

\begin{tabular}{|c|c|c|}
\hline FACTORS & $\begin{array}{l}\text { MULTIVARIATEADJUSTED } \\
\text { PREVALENCE RATIO ( } 95 \% \text { CI) }\end{array}$ & $\begin{array}{l}\mathrm{P} \\
\text { VALUE }\end{array}$ \\
\hline \multicolumn{3}{|l|}{ AGE IN YEARS } \\
\hline $\begin{array}{l}\leq 17 \\
18-29^{\mathrm{a}}\end{array}$ & $4.123(1.440-11.806)$ & $0.008^{\mathrm{b}}$ \\
\hline $30-44$ & $2.280(1.013-5.133)$ & $0.047^{\mathrm{b}}$ \\
\hline $45-59$ & $3.127(1.429-6.842)$ & $0.004^{b}$ \\
\hline $60-69$ & 4.266(1.937-9.395) & $<0.001^{b}$ \\
\hline$\geq 70$ & $7.050(3.203-15.517)$ & $<0.001^{b}$ \\
\hline \multicolumn{3}{|l|}{ SEX } \\
\hline Male & $1.264(1.201-1.605)$ & $0.045^{\mathrm{b}}$ \\
\hline \multicolumn{3}{|l|}{ SYMPTOMS } \\
\hline Breathlessness & 7.051(5.550-8.959) & $<0.001^{\mathrm{b}}$ \\
\hline \multicolumn{3}{|l|}{ NO OF SYMPTOMS } \\
\hline \multicolumn{3}{|l|}{ None $^{\mathrm{a}}$} \\
\hline 1 & $2.587(1.899-3.523)$ & $<0.001^{\mathrm{b}}$ \\
\hline 2 & $3.162(2.290-4.366)$ & $<0.001^{b}$ \\
\hline$\geq 3$ & $2.456(1.661-3.632)$ & $<0.001^{b}$ \\
\hline \multicolumn{3}{|l|}{ COMORBIDITIES } \\
\hline Chronic kidney disease & $3.079(2.305-4.112)$ & $<0.001^{\mathrm{b}}$ \\
\hline Malignancy & $2.394(1.390-4.123)$ & $0.002^{\mathrm{b}}$ \\
\hline Lung disease & $1.215(0.783-1.886)$ & 0.385 \\
\hline \multicolumn{3}{|l|}{ No DM/HT/CHD ${ }^{a}$} \\
\hline Only DM & $1.581(1.176-2.125)$ & $0.002^{\mathrm{b}}$ \\
\hline Only HT & $1.137(0.754-1.712)$ & 0.541 \\
\hline Only CHD & $1.447(0.631-3.320)$ & 0.383 \\
\hline DM WITH HT & $1.704(1.264-2.297)$ & $<0.001^{b}$ \\
\hline DM WITH CHD & $1.943(1.094-3.449)$ & $0.023^{\mathrm{b}}$ \\
\hline HT WITH CHD & $2.301(1.040-5.090)$ & $0.040^{\mathrm{b}}$ \\
\hline DM,HT,CHD & $1.580(0.946-2.640)$ & $0.080^{\mathrm{b}}$ \\
\hline $\begin{array}{l}\text { Other chronic disease [liver } \\
\text { disease,HIV, } \\
\text { TB,chronic neurological } \\
\text { disease] }\end{array}$ & $1.894(1.428-2.512)$ & $<0.001^{\mathrm{b}}$ \\
\hline
\end{tabular}

CKD-Chronic renal disease, DM- Diabetesmellitus, HT-Hypertension,CHD-Heart disease, HIV-Human immunodeficiency virus,TB- Tuberculosis.

a - reference in mutivariate logistic regression to find out multivariate adjusted prevalence ratio.

${ }^{\mathrm{b}}$ P-value $<0.05$,statistically significant.

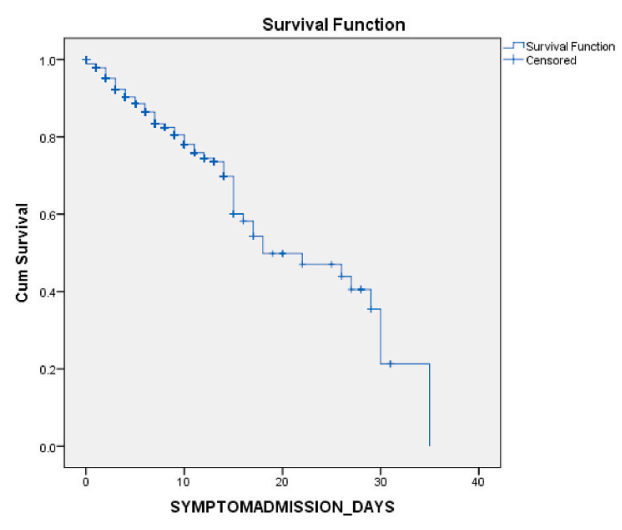

Cumulative Events for the respective number of days from symptom to admission

\begin{tabular}{|c|c|c|c|}
\hline 0 & 10 & 20 & 30 \\
\hline Death - 49 & 353 & 374 & $380 \quad 381$ \\
\hline Discharge- 362 & 4033 & 4138 & $4147 \quad 4149$ \\
\hline
\end{tabular}

Fig. 1. Survival probability of COVID positive patients based on their time of admission after their symptom onset.

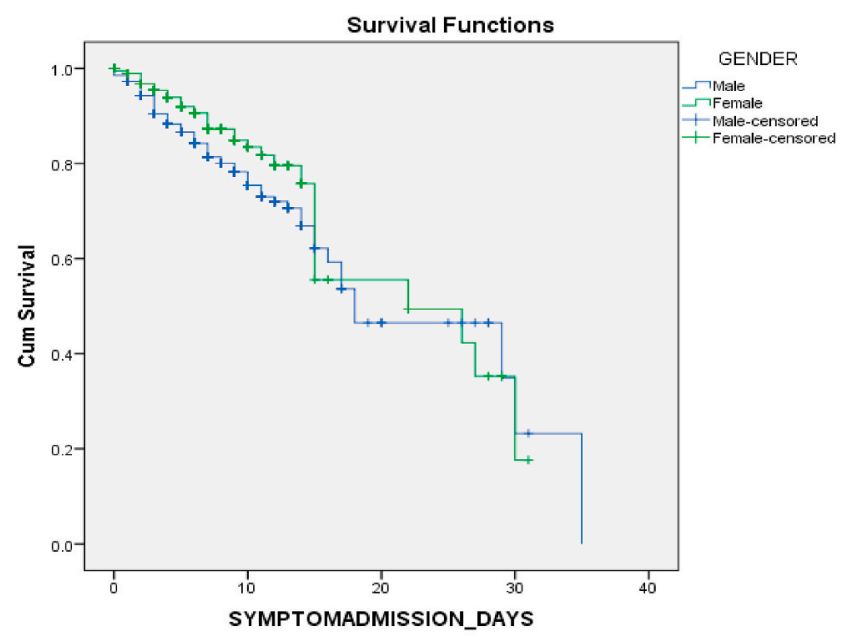

Cumulative Events forthe respective number of days from symptom to admission

\begin{tabular}{|c|c|c|c|}
\hline \multicolumn{4}{|l|}{ Male } \\
\hline Death- & 270 & 284 & 286 \\
\hline Discharge-195 & 2354 & 2427 & $2432 \quad 2433$ \\
\hline \multicolumn{4}{|l|}{ Female } \\
\hline Death- & 83 & 90 & 94 \\
\hline Discharge- 167 & 1679 & 1711 & 1716 \\
\hline
\end{tabular}

Fig. 2. Survival probability of COVID positive patients based on the time of admissionafter their symptom onset among males and females.

days. For the patients referred to us from other hospitals,date of admission in the first health care facility was considered for survival analysis.Mean duration from symptom to admission was $168.404 \mathrm{~h}$, median was $168 \mathrm{~h}$, minimum duration was $0.5 \mathrm{~h}$ and maximum was 840 h. It was evident that the Probability of survival was more than $90 \%$ when the patient got admitted within 1 week from the onset of symptom and it was less than $80 \%$ for the patients admitted between 7 and 10 days from the symptom onset and the survival probability gradually 
declined thereafter.

\section{Discussion}

COVID 19 is a relatively new and understudied disease. Hence, the data is limited. However, from our study population, the following observations were made.

The overall death rate was $8.4 \%$ and the recovery rate was $91.6 \%$. The case Fatality rate of COVID 19 varies globally as each region of the world is experiencing different stages of a pandemic.

In the present study, patients in the deceased group were much older than survivors, and univariate and multivariable logistic regression analysis revealed age $\geq 70$ years as a strong predictor for death due to COVID-19 pneumonia which is consistent with many studies conducted globally ${ }^{18,19,}{ }^{20}$ This may be due to inflammaging, immunosenescence, hyperthrombosis, and cytokine storms.

Exact mortality rates varied in hundreds of studies because they depend on testing and therapeutic interventions but it was evident from the CDC and many other studies that the mortality rate was increasing exponentially with age. ${ }^{21-26}$ Our study also had similar findings for adults more than 45 years.

In our study, there were 7 deaths in the age group $<17 y$ rs. However all those deaths occurred between 10 and 17yrsage and all patients had co-morbidities like leukemia, other carcinomas, pancytopenia with TB lymphadenitis, seizure disorder, Plummer Wilson syndrome, etc. In all those cases, it was the chronologically younger persons who were biologically older and the biological age determined the likelihood of death due to COVID-19. This is similar to a systematic review by Ludvigson et al. where deaths in children were also noted but infrequent ${ }^{27}$

The mortality rate was twice higher in men than in women in other studies ${ }^{28,29,} \cdot{ }^{30}$ Our study also found similar findings where males had a 1.26 times higher risk of dying than that of females. This may be because of the faster aging of men than women and at any chronological age, men are biologically older than women.

As expected, our analysis also revealed that patients with comorbidities had more deteriorating outcomes compared with their counterparts especially for patients with CKD, malignancy, diabetes alone, or with the combination. This is similar to a UK cross-sectional survey of 16,749 COVID 19 patients which showed that the risk of death was higher for patients with cardiac, pulmonary, and kidney disease, as well as cancer, dementia, and obesity (HRs of 1.19-1.39 after correction for age and sex). ${ }^{31}$ Also, a cohort study of 7337 patients with COVID 19 and a comparison between diabetics and non-diabetics by Zhu et al. ${ }^{32}$ in China showed that type 2 diabetics had more risk of dying and required increased interventions for their hospital stay when compared to non-diabetics.

\section{Conclusion}

To conclude, we have generated early insights into factors associated with COVID-19-related deaths using the detailed primary care records of 4530patients while maintaining privacy, in the context of a global health emergency. There are still many facts that we do not know about COVID-19 due to gaps in knowledge; therefore, many studies are underway to better understand this virus.

\section{Strength and weakness}

The greatest strengths of this study are its size and the speed at which it was conducted. The large scale of the study allows more precision on rarer exposures and multiple factors.Also, the present study explains the survival probability which would help to create awareness and therefore early admission among the public. The study also has some important limitations.Study was conducted at a single-centre hospital. A larger cohort study of patients with COVID-19 pneumonia from various health centres would help to further define the clinical characteristics. There are possibilities for some bias in this study. Interviewer bias was minimized by using a standard validated questionnaire(CIF-Case Investigation Form recommended by NCDC); Data on risk factors were collected at the time of admission even before the occurrence of the outcome and proper training was given for personnel prior to the interviews. Also, Two researchers independently reviewed the data collection forms to double-check the collected data.

Till mid of June month, almost all the COVID19 cases of Madurai district (mild/moderate/severe/asymptomatic) were admitted in our tertiary hospital and COVID19 Health Centre attached to it. Even after mid June, though many other COVID19 centres were opened in Madurai, more than $50 \%$ of COVID cases were admitted in our institute. Severe and moderate cases were received in our tertiary care hospital; asymptomatic and mild cases were admitted in our COVID Health Centre.So it was ensured that all types of cases were included in our study. This minimizes berkisonian bias.

Data were collected from all the new cases as they became COVID19 positive, hereby minimizing the incidence prevalence bias.

Hence all type of COVID patients were included,our study results can be generalized.

\section{Financial interest}

None.

\section{Funding}

This research did not receive any specific grant from funding agencies in the public, commercial or not-for- profit sectors.

\section{Data integrity}

Dataset is under the control of our institution, but it can be provided through proper channel upon requisition to corresponding author.

\section{Submission declaration}

This work is not published previously or considered for publication. Publication is approved by all authors and by responsible authuroities where work has been carried out. If accepted it will not be published elsewhere in the same form without written consent of copyright holder.

\section{Declaration of competing interest}

None.

\section{Acknowledgment}

We thank our Dean - Professor Dr.J.Sangumani (3rd Author), for his constant support and motivation throughout this study.We also thank Professor Dr.M.Natarajan,M.D.(General Medicine,Department of Medicine,GRH,Madurai and Professor Dr.K.Senthil,M.D (General Medicine), Department of Medicine,GRH,Madurai for their support in technical and administrative aspects. We also thank all other Post Graduates and CRRI's of the Institute of Community medicine who helped us in data collection.
Abbreviations
COVID19 Corona virus Disease-19
WHO World Health Organization
RNA Ribonucleic acid
COPD Chronic Obstructive Pulmonary Disease
CKD Chronic Kidney Disease
CAD Coronary Artery Disease
NCDC National Centre for Disease Control 
CRRI Compulsory Rotatory Residential Internship

SPSS Statistical Package for the Social Science

NCD Non Communicable Disease

PR Prevalence Ratio

Sp02 Saturation of peripheral Oxygen

HIV Human Immunodeficiency Virus

CDC Centre for Disease Control

MOHFW Ministry of Health and Family Welfare

\section{References}

1 Wuhan Municipal Health Commission (WMHC). Report of Clustering Pneumonia of Unknown Etiology in Wuhan City; 2020. Available from: http://wjw.wuhan.gov.cn/fro nt/web/showDetail/2019123108989. Accessed January 1, 2020.

2 COVID-19 public health emergency of international concern (PHEIC) global research and innovation forum [Internet] [cited 2020 Aug 17], Available from: https://www. who.int/publications/m/item/COVID-19- public-health-emergency-of-internationalconcern-(pheic)-global-research-and-innovation-forum.

3 https://www.worldmeters.info/coronavirus/?utm_campaign=homeAdvegas1?.

4 https://stopcorona.th.gov.in/.

5 https://www.indiatoday.in/india/story/first-coronavirus-death-in-india-karnatakaman-1654953-2020-03-12.

6 https://indianexpress.com/article/india/first-COVID-19-death-reported-in-tamil-na du-6331895/.

7 Li X, Xu S, Yu M, et al. Risk factors for severity and mortality in adult COVID-19 inpatients in Wuhan. J Allergy Clin Immunol. $2020 \mathrm{Jul} ; 146(1): 110-118$. https://doi. org/10.1016/j.jaci.2020.04.006. Epub 2020 Apr 12. PMID: 32294485; PMCID: PMC7152876.

8 medRxiv 2020.05.06.20092999; doi: https://doi.org/10.1101/2020.05.06 20092999.

9 Islam MdZ, Riaz BK, Islam AS, et al. Risk Factors Associated with Morbidity and Mortality Outcomes of COVID-19 Patients on the 14th and 28th Day of the Disease Course: A Retrospective Cohort Study in Bangladesh [Internet]. Infectious Diseases (Except HIV/AIDS); 2020 Aug [cited 2021 Jan 20]. Available from: http://medrxiv.org/loo $\mathrm{kup} / \mathrm{doi} / 10.1101 / 2020.08 .17 .20176586$.

10 http://cghealth.nic.in/ehealth/COVID19/documents/COVID19Guidelines(IDSP) AndInformation/Information\%20and\%20Guideline/Corona\%20ICMR\%20Froms\% 20and\%20Guideline/8._Case_Investigation_form_nCoV.pdf.

11 Updated guidelines on clinical management of COVID19. Dated:17/03/2020, available from: https://www.mohfw.gov.in/.

12 Revised national clinical management guidelines for COVID19. Dated: 31/03/2020, available from: https://www.mohfw.gov.in/.

13 Clinical management protocol for COVID19. Dated: 13/06/2020, available from: https://www.mohfw.gov.in/.

14 Dated: 27/06/2020 Clinical management protocol for COVID19. available from: https://www.mohfw.gov.in/.

15 Updated clinical management protocol for COVID19. Dated: 03/07/2020, available from: https://www.mohfw.gov.in/.

16 Discharge policy for suspect or confirmed novel coronavirus (2019-nCoV) cases. Dated: 17/03/2020, available from: https://www.mohfw.gov.in/.
17 Updated revised discharge policy for COVID19. Dated: 08/05/2020, available from: https://www.mohfw.gov.in/.

18 Huang C, Wang Y, Li X, et al. Clinical features of patients infected with 2019 novel coronavirus in Wuhan, China. Lancet. 2020. https://doi.org/10.1016/S0140-6736 (20)30183-5.

19 Chen NS, Zhou M, Dong X, et al. Epidemiological and clinical characteristics of 99 cases of 2019 novel coronavirus pneumonia in Wuhan, China: a descriptive study. Lancet. 2020. https://doi.org/10.1016/S0140-6736(20)30211-7.

20 Wang DW, Hu B, Hu C, et al. Clinical characteristics of 138 hospitalized patients with 2019 novel coronavirus-infected pneumonia in Wuhan, China. J Am Med Assoc. 2020. https://doi.org/10.1001/jama.2020.1585.

21 Sargiacomo C, Sotgia F, Lisanti MP. COVID-19 and chronological aging: senolytics and other anti-aging drugs for the treatment or prevention of corona virus infection? Aging. 2020;12:6511-6517. https://doi.org/10.18632/aging.103001 PMID: 32229706 .

22 Leung C. Risk factors for predicting mortality in elderly patients with COVID-19: a review of clinical data in China. Mech Ageing Dev. 2020;188:111255. https://doi.org/ 10.1016/j.mad.2020.111255 PMID:32353398.

23 Zhou F, Yu T, Du R, et al. Clinical course and risk factors for mortality of adult inpatients with COVID-19 in wuhan, China: a retrospective cohort study. Lancet 2020;395:1054-1062. https://doi.org/10.1016/S0140-6736(20)30566-3PMID: 32171076.

$24 \mathrm{Wu}$ C, Chen X, Cai Y, et al. Risk factors associated with acute respiratory distress syndrome and death in patients with coronavirus disease 2019 pneumonia in wuhan, China. JAMA Intern Med. 2020. https://doi.org/10.1001/jamainternmed.2020.0994 PMID:32167524 [Epub ahead of print].

25 Lauc G, Sinclair D. Biomarkers of biological age as predictors of COVID-19 disease severity. Aging. 2020;12:6490-6491. https://doi.org/10.18632/aging.103052PMID: 32268300 .

26 Banerjee A, Pasea L, Harris S, et al. Estimating excess 1-year mortality associated with the COVID-19 pandemic according to underlying conditions and age: a population-based cohort study. Lancet. 2020;395:1715-1725. https://doi.org/ 10.1016/S0140-6736(20)30854-0PMID:32405103.

27 Ludvigsson JF. Systematic review of COVID-19 in children showsmilder cases and a better prognosis than adults. Acta Paediatr. 2020;109:1088-1095. https://doi.org/ 10.1111/apa.15270. . Accessed April 20, 2020. https://onlinelibrary.wiley.com/do i/full/10.1111/apa.15270.

2821 Gebhard C, Regitz-Zagrosek V, Neuhauser HK, Morgan R, Klein SL. Impact of sex and gender on COVID-19 outcomes in europe. Biol Sex Differ. 2020;11:29. https:// doi.org/10.1186/s13293-020-00304-9 PMID:32450906.

29 Jin JM, Bai P, He W, et al. Gender differences in patients with COVID-19: focus on severity and mortality. Front Public Health. 2020;8:152. https://doi.org/10.3389/ fpubh.2020.00152 PMID:32411652.

30 Blagosklonny MV. Why men age faster but reproduce longer than women: mTOR and evolutionary perspectives. Aging. 2010;2:265-273. https://doi.org/10.18632/ aging.100149PMID:20519781.

31 24. Docherty AB, et al. Features of 16,749 hospitalised UK patients with COVID-19 using theISARIC WHO clinical characterisation protocol. 2020. https://doi.org/10.1101/ 2020.04.23.20076042. Preprint at medRxiv

32 Zhu L, She Z-G, Cheng X, Qin J-J, Zhang X-J, et al. Association of blood glucose control and outcomes in patients with COVID-19and pre-existing type 2 diabetes. Cell Metabol; 2020. https://www.sciencedirect.com/science/article/pii/S15504131203 02382. Accessed May 30, 2020. 